\title{
The potential impact of new generation transgenic methods on creating rabbit models of cardiac diseases
}

\author{
Bősze Z. ${ }^{1,}$, P. Major ${ }^{1}$, I. Baczkó ${ }^{2}$, K.E. Odening ${ }^{3}$, L. Bodrogi ${ }^{2,1}$, L. Hiripi ${ }^{1}$, A.Varró ${ }^{2}$ \\ ${ }^{1}$ Rabbit Genome and Biomodel Group, NARIC-Agricultural Biotechnology Institute, H-2100 \\ Gödöllő, Hungary; ${ }^{2}$ Department of Pharmacology \& Pharmacotherapy, University of Szeged, \\ H-6720 Szeged, Hungary; ${ }^{3}$ Department of Cardiology and Angiology I, Heart Center \\ University of Freiburg, D-79106 Freiburg, Germany
}

Corresponding author

Zsuzsanna Bősze

Rabbit Genome and Biomodel group, Animal Biotechnology Department of NARIC-

Agricultural Biotechnology Institute, H-2100 Gödöllő, Hungary

E-mail address: bosze@abc.hu 


\section{Contents}

1. Overview of the cardiac disease transgenic rabbit models, created with pronuclear microinjection

2. Potential and advantages of transposon mediated additive transgenesis

3. The targeted genome engineering/ designer nuclease family

3.1. RNA-Guided Nucleases

3.2. Zink finger nuclease (ZFN)

3.3. Transcription activator-like effector nuclease (TALEN)

4. Conclusive remarks and future directions 


\begin{abstract}
Since the creation of the first transgenic rabbit thirty years ago, pronuclear microinjection remained the single applied method and resulted in numerous important rabbit models of human diseases, including cardiac deficiencies, albeit with low efficiency. For additive transgenesis a novel transposon mediated method, e.g., the Sleeping Beauty transgenesis, increased the efficiency, and its application to create cardiac disease models is expected in the near future. The targeted genome engineering nuclease family, e.g., the zink finger nuclease (ZFN), the transcription activator-like effector nuclease (TALEN) and the newest, clustered regularly interspaced short palindromic repeats (CRISPR) with the CRISPR associated effector protein (CAS), revolutionized the non-mouse transgenesis. The latest gene-targeting technology, the CRISPR/CAS system, was proven to be efficient in rabbit to create multigene knockout models. In the future, the number of tailor-made rabbit models produced with one of the above mentioned methods is expected to exponentially increase and to provide adequate models of heart diseases.
\end{abstract}

Keywords: Sleeping beauty transposon, designer nucleases, knockout, knock-in, transgenic rabbit 
1. Overview of the cardiac disease transgenic rabbit models created with pronuclear microinjection

Since the creation of the first transgenic rabbit thirty years ago (Hammer et al., 1985), pronuclear microinjection remained the single applied method and resulted in numerous important rabbit models of human diseases, with a variable (see Table 1), but in general low efficiency (Duranthon et al., 2012). These transgenic rabbit models were emerging as one of the most relevant experimental model systems for cardiovascular diseases. The lipid metabolism and the way atherosclerosis develops in rabbits are similar to that of the human (Fan et al., 2015). Since atherosclerosis and ischemic heart disease are among the leading causes of death in developed countries, most transgenic rabbit models were created in this area of cardiovascular diseases. The transgenic rabbit models of lipid metabolism and atherosclerosis established to date are listed in Table 1. Rabbit models of atherosclerosis and myocardial infarction are described in this issue by Baumgartner et al. and were recently reviewed by (Fan et al., 2015). Transgenic rabbit models have been established for hypertrophic cardiomyopathy (HCM), a relatively common inherited heart disease, that can lead to serious ventricular arrhythmias and is the most frequent cause of sudden cardiac death in young people (Decker et al., 2009). Mutations of all known sarcomeric proteins, the structural components of heart can cause HCM. The protein composition of the rabbit heart is closer to humans than rodents: In the human heart the $\beta$-myosin heavy chain $(\beta-\mathrm{MyHC})$ comprises $90 \%$ of the total myofibrillar myosin, in the rabbits heart similarly to humans, $80 \%$ is made of $\beta-\mathrm{MyHC}$, in contrast to mouse heart, the other myosin isoform, $\alpha$-myosin heavy chain ( $\alpha$-MyHC) predominates with 95\% (Marian, 2005). Different transgenic mouse models were created, among which none reproduced left ventricular hypertrophy, the hallmark of HCM (Marian, 2005).The first rabbit model of HCM was created by (Marian et al., 1999) 
with pronuclear microinjection carrying a common point mutation of $\beta$-myosin heavy chain R400Q (Table 1). Transgenic rabbits recapitulated the phenotype and primary abnormalities observed in human carriers: myocyte disarray and interstitial fibrosis, along with left ventricular hypertrophy. The usefulness of this transgenic rabbit strain in translational studies was underlined later, when it was used to prove, that simvastatin treatment induces regression of hypertrophy and fibrosis (Patel et al., 2001) and to evaluate the effect of atorvastatin in preventing cardiac hypertrophy (Senthil et al., 2005). Another transgenic rabbit model was created with pronuclear microinjection of the mutant cardiac troponin I (cTnI-R146G). R146G is a missense mutation causing HCM in human carriers (Sanbe et al., 2005). The cTnI-G146 rabbits recapitulated the phenotype of human HCM, including cardiac hypertrophy, myocyte disarray, interstitial fibrosis, and enhanced myofibrillar $\mathrm{Ca}^{2+}$ sensitivity. In order to better understand the role of the myosin isoforms, the $\alpha$-myosin heavy chain was overexpressed in the transgenic rabbit heart, where it reached $15-40 \%$ of the total myofibrillar myosin, contrary to the normal adult human ventricle, where it is composed of 5-10\% (James et al., 2000). The incorporation of $40 \%$ alpha-MHC led to greater myofilament power production and more rapid crossbridge cycling, which facilitate ejection and relengthening during short cycle intervals, and thus protected against tachycardia-induced cardiomyopathy (Suzuki et al., 2009)

Another emerging area of cardiac disease models are the so called inborn arrhythmogenic diseases such as long QT syndrome (LQTS). Relevant transgenic rabbit models created with pronuclear microinjection are reviewed by Lang and Odening in this issue and listed in Table 1. In brief, transgenic LQTS rabbit models selectively overexpressing dominant-negative pore mutants of the human KvLQT1 (KvLQT1-Y315S, LQT1, loss of IKs) or HERG channels (HERG-G628S, LQT2, loss of IKr) in the heart completely mimic the human LQTS phenotype with QT prolongation, spontaneous sustained pVTs and SCD 
(Brunner et al., 2008; Odening et al., 2008). The first LQT5 transgenic rabbit model expressing a mutant human minK (KCNE1-G52R) protein exhibits increased cardiac repolarization instability and may thus be very useful for proarrhythmia studies on drugs challenging "silent” LQTS subjects clinically (Major et al., 2016). 
Table 1. Cardiac disease transgenic rabbit models created with pronuclear microinjection

\begin{tabular}{|c|c|}
\hline \multicolumn{2}{|c|}{ Models for lipid metabolism and atherosclerosis } \\
\hline $\begin{array}{c}\text { Overexpressed mutant or wild type protein and } \\
\text { transgenic efficiencies* }\end{array}$ & References \\
\hline - Hepatic lipase & (Fan et al., 1994) \\
\hline - Apolipoprotein B100 A: 0.25; B: $10 \%$ & (Fan et al., 1995) \\
\hline - 15-Lipoxygenase & (Shen et al., 1996; Shen et al., 1995) \\
\hline - Matrix metalloproteinase & (Liang et al., 2006; Yamanaka et al., 1995) \\
\hline - Apolipoprotein A1 & (Boullier et al., 2001; Duverger et al., 1996) \\
\hline - Lecithin-cholesterol acyltransferase & (Hoeg et al., 1996) \\
\hline - Apolipoprotein E2 & (Huang et al., 1997) \\
\hline Apolipoprotein E3 & (Fan et al., 1998) \\
\hline - Lipoprotein lipase & (Fan et al., 2001; Ichikawa et al., 2004) \\
\hline - Apolipoprotein A A: $0.71 \%$; B: $11.7 \%$ & $\begin{array}{c}\text { (Fan et al., 2001; Kitajima et al., 2007; Rouy } \\
\text { et al., 1998; Senthil et al., 2005) }\end{array}$ \\
\hline Apolipoprotein A2 & (Koike et al., 2009) \\
\hline Apolipoprotein CIII & (Ding et al., 2011) \\
\hline $\begin{array}{l}\text { - Vascular Endothelial Growth Factor (VEGF) } \\
\text { A: } 0.33 \% ; \mathrm{B}: 4.37 \%\end{array}$ & (Kitajima et al., 2005; Liu et al., 2007) \\
\hline - Matrix metalloproteinase [MMP]-12 & (Liang et al., 2006; Yamada et al., 2008) \\
\hline - Plasma phospholipid transfer protein & (Masson et al., 2011) \\
\hline C-reactive protein (CRP) & (Matsuda et al., 2011) \\
\hline \multicolumn{2}{|c|}{ Models of altered sarcomeric proteins } \\
\hline $\begin{array}{l}\text { - } \beta-\mathrm{MyHC}-\mathrm{Q}^{403} \text { ( } \beta \text {-myosin heavy chain) (R400Q) } \\
\mathrm{A}: 0.65 \% ; \mathrm{B}: 21 \%\end{array}$ & $\begin{array}{c}\text { (Marian et al., 1999; Patel et al., 2001; } \\
\text { Senthil et al., 2005) }\end{array}$ \\
\hline - cTnI-G146Cardiac troponin I (R146G) & (Sanbe et al., 2005) \\
\hline - $\alpha-\mathrm{MyHC}(\alpha-\mathrm{myosin}$ heavy chain) & (James et al., 2000; Suzuki et al., 2009) \\
\hline \multicolumn{2}{|c|}{ Models of inborn arrhythmogenic disease long QT syndrome } \\
\hline - $\mathrm{KCNQ1/KvLQT1} \mathrm{(KvLQT1-Y315S,} \mathrm{LQT1,} \mathrm{loss} \mathrm{of} \mathrm{IKs)}$ & (Brunner et al., 2008; Odening et al., 2008) \\
\hline - $\mathrm{KCNH} 2 / \mathrm{HERG}$ (HERG-G628S, LQT2, loss of IKr) & (Brunner et al., 2008; Odening et al., 2008) \\
\hline $\begin{array}{l}\text { - KCNE1/minK (KCNE1-G52R, LQT5, altered IKs) } \\
\text { A: } 0.80 \% \text {; B: } 10.5 \%\end{array}$ & (Major et al., 2016) \\
\hline
\end{tabular}

* transgenic efficiencies are indicated where relevant data were published A: \% transgenic of total injected and transplanted and B: \% transgenic of total born alive) 


\section{Potential advantages of transposon mediated additive transgenesis}

DNA transposons were primarily developed for gene therapeutic aims, but turned out to be applicable in mammalian transgenesis as well. DNA transposons are mobile genetic elements, which can integrate into the genome of the host cell by a simple "cut and paste" mechanism. The newly developed transposon vectors enable to cut out the transgene of interest flanked by inverted terminal repeats from the plasmid and integrate it into the host genome. The excisions from the plasmid vector and the integration to a genomic region at special target sequences are catalysed by a transposase. The transposase can be provided on a plasmid DNA or even better as an in vitro synthesized transcript. Different transposon based systems were used to produce transgenic mammals, but the Sleeping Beauty was the first and to date the only one which was successfully applied in rabbit Figure 1 (Ivics et al., 2014; Katter et al., 2013).

Sleeping Beauty was reconstructed by molecular methods from a fish and belongs to the TC1/mariner family of DNA transposons (Izsvak et al., 2000). The hyperactive variant (SB 100X) was later developed to increase its efficacy in biotechnological processes (Mates et al., 2009). The SB100X vector system can be used in non dividing cells also with low silencing activity in mammalian cells (Grabundzija et al., 2010). The Sleeping beauty transposon directs integration into a genomic region quasi randomly (its target sequence is AT) avoiding coding region of genes ("gene free zones" or introns). To create the first transgenic rabbits with Sleeping Beauty transposon system $0.4 \mathrm{ng} / \mathrm{ul}$ circular pT2/Venus plasmid (Venus is a reporter gene driven by CAG promoter) and $5 \mathrm{ng} / \mathrm{ul}$ Sleeping Beauty 100X transposase mRNA cocktail was microinjected into the pronucleus of early rabbit zygotes (Katter et al., 2013). Due to the transposase mediated cut and paste mechanism, the founder rabbits carry one single transgene copy at each integration site contrary to the plasmid based pronuclear microinjection when the transgene integrates in head-to-tail tandems with 
copy numbers in the range of 2-100 copies or above. The number of integration sites were also examined and found to vary between 1 to 3 in founder animals. It is an apparent advantage of transposon based transgenesis, since a transgenic rabbit which integrated a single copy mutant human gene in hemizygote form will be better comparable at gene expression levels to the modelled individuals, who harbour one normal and one mutant gene. The other advantage of the transposon based transgenesis is the reported transgenic/total born alive $15.1 \%$ efficiency together with the $1.48 \%$ transgenic out of total injected and transplanted, which is higher than the average efficiencies obtained with pronuclear

microinjection (Table 1). The above mentioned characteristics makes the Sleeping Beauty transposon based transgenesis to an attractive alternative method of pronuclear microinjection, to create monogenic cardiac disease models with additive transgenesis in a cost and time saving way.

\section{The targeted genome engineering/designer nuclease family}

In the last decade several new genome editing technologies have been developed. The most significant systems are the zinc finger nucleases (ZNFs), the transcription activator-like effector nucleases (TALENs) and the RNA guided nucleases, represented by the CRISPR/Cas9 endonuclease. The adaptation of designer nucleases to targeted genetic modification of mammalian genome has changed the potential of transgenic technology via opening new perspectives both in laboratory and livestock animals during the last 5 years and has already hit rabbit biotechnology too. The prerequisite for targeted gene modification in rabbit, like in any other species was a high quality annotated genome sequence. The Broad Institute released the $7 \mathrm{x}$ coverage OryCun2.0 database in 2009 , which is publicly available. The reference sequence for the rabbits genome was established using a female rabbit of the partially inbred Thorbecke strain. It should be emphasized that with this available database, 
the targeted gene needs to be resequenced in most of the cases from the genomic DNA of the selected rabbit breed or hybrid, before planning the DNA nuclease vectors. Current efforts at different laboratories are aiming to complete the genomes of all experimental rabbit breeds, including RNA sequence analysis (Fan et al., 2015; Miller et al., 2014).

The designer nuclease technologies share a couple of common characteristics.

1. They are able to recognize DNA sequences with highly flexible design options in order to make them strictly specific to unique DNA sequences with few limitations.

2. Two out of the three systems involve a restriction enzyme which in a form of a dimer is able to cut double stranded DNA.

3. As a consequence of a DNA double strand break (DSB) the cells/organism own repair system is activated and uses the most common DNA repair system of non-homologous end joining (NHEJ) which most of the cases results in small deletions or insertions (indel) at the point of the DSB in the targeted gene. This event disrupts gene function by causing a frame shift mutation and/or emergence of a termination signal. The other DSB repair mechanism is called homology-directed repair (HDR) that occurs in the presence of a homologous DNA template, provided by the experimenter.

\subsection{RNA guided nucleases - Clustered regularly interspaced short palindromic repeats} (CRISPR) with its associated effector protein (CAS)

The CRISPR/CAS RNA guided nuclease system is the most recent among the three available designer nuclease methods, but due to its simplicity and effectiveness it is the most popular with increasing number of transgenic rabbit strains created with this method. The CRISPR associated protein-9 (Cas9) nuclease gene was isolated from a bacteria Streptococcus pyogenes and along with other CAS genes has essential role in adaptive immunity, enabling the organisms to respond and eliminate invading genetic material. The CRISPRs represent the 
memory of the system, which based on previous infection create a library of short, directly repeating nucleotide sequences that alternate with small unique DNA fragments (Bolotin et al., 2005). The effector CAS proteins process the CRISPR sequences into small RNAs and cleave the invading DNA molecules which match the produced small RNAs (Haurwitz et al., 2010). In the genome editing tool, which is based on this prokaryotic system the CRISPR RNA (crRNA) and the trans-activating RNA (tracrRNA) were fused into a synthetic small guide RNA (sgRNA), which harbours a hairpin RNA structure linked to an approximately $20 \mathrm{bp}$ long target DNA homologous sequence. Cas9 is able to cleave both strands of the targeted DNA after detecting Watson\&Crick homologous base pair match with the sgRNA (Fig 2a)(Charpentier and Doudna, 2013). A high fidelity variant of Cas9 (Cas9-HFI) was published in early 2016, which was designed to reduce non-specific DNA contacts and hereby significantly reduce the off- target effect by the CRISPR-CAS-HFI nucleases (Kleinstiver et al., 2016). .

The first transgenic rabbits produced by RNA-Guided Nucleases (CRISPR/Cas9) were reported in 2014. Yang and co-workers published the successful knockout of nine rabbit genes in in vitro cultured rabbit embryos (Yang et al., 2014). Four gene's specific RNA mixture was used to create founders and eventually establish novel knockout rabbit lines (CD36, low density lipoprotein receptor, apolipoprotein E and ryanodine receptor 2). Some founder rabbit carried a biallelic mutation for the targeted gene, with other words, it was possible to create a homozygote knockout rabbit model at one-step. Moreover the authors could not detect off-target effects at least in the potential exons. Importantly, CD36 (Febbraio et al., 2000), low density lipoprotein receptor (Ishibashi et al., 1993) and apolipoprotein E have a role in atheroscleorsis and therefore the gene deleted rabbit will be or are already important models of different cardiac diseases in translational studies or gene therapy. CD36 is a member of the class B scavenger receptor family of cell surface proteins, and using 
genetically modified rodents a clear role for CD36 in fatty acid metabolism and heart disease was identified (Febbraio et al., 2000). Mutations in the ryanodine receptor 2 gene, the fourth gene deleted by Yang and co-workers (2014) are associated with catecholaminergic polymorphic ventricular tachycardia, stress-induced polymorphic ventricular tachycardia and arrhythmogenic right ventricular dysplasia (Bround et al., 2012).

The pilot, single-gene editing studies were followed a few months later with multigene knockout rabbit models in which three or five genes were simultaneously targeted in a single embryo, with high efficiency, underlining the power of the CRISPR/CAS technology (Yan et al., 2014). Among the genes deleted the Tikil gene, - which is a Wnt inhibitor and required for embryonic patterning, as well as organogenesis- is noticeably absent in the rodent lineage, but is present in Lagomorphs and all other vertebrate/mammalian species examined (Reis et al., 2014), outlining the special advantage of rabbit models in those category of genes, where the rodent ortholog of the human gene is missing. The efficiency and flexibility of the CRISPR/Cas9 system have called forth the possibility to commercially order gene targeted rabbits (http://www.sageresearchlabs.com Useful website to design target site for use with the CRISPR system: http://www.ecrisp.org/E-CRISP/

\subsection{Zinc-finger nucleases - ZFN}

Zinc-finger nucleases have two domains: a DNA-binding zinc finger protein domain which is a tandem of 3-6 zinc finger-binding motifs each recognizing a 3 nucleotide sequence adding up to a specific 9-18 bp sequence. This predesigned, programmable protein domain is fused to a nuclease domain such as the FokI, type II endonuclease (Bibikova et al., 2001). The protein domain provides target specificity for the nuclease domain which in a form of a dimer cleaves DNA, leaving double strand breaks (Fig 2b) (Mani et al., 2005). The cell using its own repair 
pathways either rejoins the DSB with non-homologous end joining mainly resulting in deletions or insertions (Lieber, 1999). In most of the cases indels disrupt gene function resulting in a gene knock out cell. The other cellular pathway to fix the DSB is homologous recombination that occurs when a homologous template is present. Adding it to the system artificially a knock in or allele exchanged cell can be produced.

Major drawback of the first available ZNF systems is the assembly and testing of the protein domain. It is a time consuming and laborious process that requires robust laboratory settings for designing and testing the individual and the tandemized ZFNs. The first transgenic rabbit with targeted gene modification was created with ZFN technology: the immunoglobulin M (IgM) locus was disrupted. The functional knock-out phenotype was established with high efficiency in a heritable way (Flisikowska et al., 2011). This rabbit model could be the first step to create a transgenic rabbit platform for the production of therapeutic human polyclonal antibodies. The first ZFN targeted transgenic rabbit with cardiovascular phenotype was an Apolipoprotein C-III knockout rabbit (Yang et al., 2013). Apolipoprotein E KO rabbits were also produced using ZFN technology. The knockout rabbits had drastically elevated cholesterol and moderately increased triglyceride levels, mimicking symptoms in human heart disease (Ji et al., 2015).

Useful websites for adapting ZFN technology:http://www.sigmaaldrich.com/life$\underline{\text { science/learning-center/biowire/biowire-fall-2010/zfn-donor-design.html }}$ http://www.bioinformatics.org/primerx/cgi-bin/DNA_1.cgi

\subsection{Transcription activator-like effector nucleases - TALENs}

TALENs similarly to ZFNs build up of two domains, a protein and a nuclease domain. The protein domain is an artificial sequence-specific DNA-binding domain that can be costumized to any DNA sequence. It is originated from proteins secreted by Xanthomonas bacteria during colonization of its host plant. 
These proteins are highly conserved repeats derived from transcription activator-like effectors (TALE). Each individual TALE protein consists of 33-35 highly conserved amino acid repeats which are able to recognize and bind a single base of DNA. The base specificity of each TALE typically found at the 12 and 13 position of the domain termed repeat-variable diresidues (RVDs)(Streubel et al., 2012). Building up an array of TALEs it can recognize and bind DNA with sequence specificity. The TALE array is flanked by additional TALE-derived domains at the amino and carboxy-terminal. The nuclease domain, the restriction endonuclease FokI is fused to this artificial TALE array and after recognition and binding of DNA forms a dimer and cleaves double stranded DNA ( Fig 2c)(Joung and Sander, 2013).

RAG-1 and RAG-2 deficient rabbits were created with adapting TALEN method to this species at first (Song et al., 2013). With the targeted gene deletion transgenic rabbits without mature $\mathrm{T}$ and $\mathrm{B}$ cells were created. The efficiency of genetic modification was extremely high. These rabbits could be used as valuable animal models for drug discovery. Useful websites for adapting TALEN technology https://tale-nt.cac.cornell.edu/; http://www.e-talen.org/E-TALEN/index.html

\section{Conclusive remarks and future directions}

Rabbit is model animal and -including the transgenic rabbits- it already has and will have its place among the different models of cardiac diseases. Table 2 summarizes the pros- and cons for the transgenic rabbit in the light of other alternatives. The available rabbit breeds as starting genetic material for transgenesis are not inbreds, therefore the rabbits within the transgenic strains might have high inter-individual variations, which should be taken into consideration. 
Table 2 Comparative advantages of transgenic animal models of cardiac diseases

\begin{tabular}{|c|c|c|}
\hline Species & Advantages & Best for \\
\hline Small rodents: mice, rat & $\begin{array}{l}\text { *shorter life span, shorter } \\
\text { gestation periods } \\
\text { *lower interindividual } \\
\text { variability } \\
\text { *lower cost }\end{array}$ & $\begin{array}{l}\text { *studying gene expression } \\
\text { and function } \\
\text { *assessment of } \\
\text { pharmacological therapies } \\
\text { (rat) }\end{array}$ \\
\hline Medium size: rabbit & $\begin{array}{l}\text { *fill the gap between small and } \\
\text { large animal models } \\
\text { *relatively inexpensive } \\
\text { compared to large animals, } \\
\text { *housing and maintenance } \\
\text { more affordable in laboratory } \\
\text { settings } \\
\text { *easy to breed } \\
\text { *phylogenetically closer to } \\
\text { primates than rodents } \\
\text { *the more diverse genetic } \\
\text { background allows a better } \\
\text { approximation to humans }\end{array}$ & $\begin{array}{l}\text { *translational research: drug } \\
\text { testing, diagnostics } \\
\text { *transgenic model to study } \\
\text { the development of coronary } \\
\text { and cardiovascular diseases } \\
\text { and conditions } \\
\text { *study the ethiology of } \\
\text { atherosclerosis } \\
\text { *testing endovascular } \\
\text { therapeutic devices }\end{array}$ \\
\hline $\begin{array}{l}\text { Large animal: porcine, } \\
\text { monkey }\end{array}$ & $\begin{array}{l}\text { *similar plasma lipoprotein } \\
\text { profile to humans } \\
\text { * similar cardiac anatomy and } \\
\text { physiology to humans }\end{array}$ & $\begin{array}{l}\text { *drug testing, xenografting } \\
* \text { development and testing of } \\
\text { imaging technologies and } \\
\text { interventional cardiology }\end{array}$ \\
\hline
\end{tabular}

Contrary to the mouse, genetically modified embryonic stem cells or induced pluripotent stem cells do not contribute to germline transmission in rabbit, moreover to date the somatic cloning worked at very low efficiency in this species (Zakhartchenko et al., 2011), however recently the first knock out rabbit by nuclear transfer has been created (Yin et al., 2015). Pronuclear microinjection remained the single applied method for twenty five years. The recently published SB transposon mediated transgenesis could be an efficient alternative to create rabbit models with human genes carrying a dominant negative mutation, SB transgenesis results in one copy integration per site, compared with the less advantageous tandem transgene arrangements in case of traditional pronucear microinjection. In a cardiac disease model, which might be created with SB transgenesis, the animal will have its own wild type ortholog biallelic gene and upon this background optimally one or two copies of the 
transgene. Those kind of transgenic rabbits offer a relatively quick and cheap way to analyse the phenotype of a newly identified mutation e.g. a novel LQTS mutation identified in patients.

The designer nucleases opened another avenue and made possible to remove-knockout- one or more rabbit genes in a single founder animal or even replace the rabbit gene with the mutant human ortholog gene (knock-in).

Due to the relative low number of transgenic rabbit strains created with either of the designer nucleases, limitations of those novel technologies could be mainly extrapolated from results obtained in cell lines. One potential unwanted effect is creation off-target mutations in the rabbit genome. Recent publications offer safer gene-editing solutions in cell lines, for example via reducing the long-time expression of the Cas9 protein packed in lentivirus (Choi et al., 2016) or with the high fidelity variant of the CRISPR/CAS9 nuclease with reduced non-specific DNA contacts (Kleinstiver et al., 2016). It is worth to mention, that contrary to the most recent and effective CRISPR/CAS9 nuclease method, the more laborious and time consuming ZFN based technology already reached the level of specificity, that ex vivo and in vivo clinical trails were permitted by the authorities and were performed successfully (Sharma et al., 2015; Tebas et al., 2014)

In the future more and more suitable cardiac disease rabbit models could be used to analyse the knockout/knock-in phenotype, to perform drug tests or gene therapy. Overall the new generation transgenic methods described above enable the fast production and as a consequence the availability of multiple specialized transgenic animal strains to model many human diseases, including cardiac diseases. 


\section{Legend for Figures}

Figure 1. The Sleeping Beauty transposon system (Katter et al., 2013)

A: The binary system comprise a transposon construct with the gene of interest (promoter and coding region) flanked by inverted terminal repeats (TIR) and the transposase helper protein. The transposase is introduced as in vitro synthesized $m R N A$.

B: Following delivery of the components to the one cell embryos by microinjection, the transposase mRNA translated by the cellular machinery to transposase protein (green cube), binds the TIRs flanking the gene of interest (GOI) and catalyzes the excision and subsequent random genomic integration of the gene of interest flanked by TA sites, in one copy per integration site.

Figure 2 Schematic description of the designer nucleases

A: The clustered regularly interspaced short palindromic repeats (CRISPR) with its associated effector protein (CAS 9), sgRNA: a hairpin RNA structure linked to an approximately 20 bp long target DNA homologous sequence; PAM: protospacer adjacent motif, a DNA sequence motif determined by the CAS protein (TGG for Cas 9 )

B: The zinc-finger nuclease (ZFN)

C: The transcription activator-like effector nuclease (TALEN)

\section{Acknowledgements}

This work was supported by the Hungarian Scientific Research Fund (OTKA CNK 77855 and OTKA NK 104331 to A.V., OTKA NN 110896 to I.B., OTKA NK 104397 to Z.B) and by the RGB-Net COST Action TD1101. 


\section{References}

Bibikova, M., Carroll, D., Segal, D.J., Trautman, J.K., Smith, J., Kim, Y.G. and Chandrasegaran, S., 2001. Stimulation of homologous recombination through targeted cleavage by chimeric nucleases, Mol Cell Biol. 21, 289-97.

Bolotin, A., Quinquis, B., Sorokin, A. and Ehrlich, S.D., 2005. Clustered regularly interspaced short palindrome repeats (CRISPRs) have spacers of extrachromosomal origin, Microbiology. 151, 2551-61.

Boullier, A., Hennuyer, N., Tailleux, A., Furman, C., Duverger, N., Caillaud, J.M., Castro, G., Fievet, C., Fruchart, J.C. and Duriez, P., 2001. Increased levels of high-density lipoprotein cholesterol are ineffective in inhibiting the development of immune responses to oxidized low-density lipoprotein and atherosclerosis in transgenic rabbits expressing human apolipoprotein (apo) A-I with severe hypercholesterolaemia, Clin Sci (Lond). 100, 343-55.

Bround, M.J., Asghari, P., Wambolt, R.B., Bohunek, L., Smits, C., Philit, M., Kieffer, T.J., Lakatta, E.G., Boheler, K.R., Moore, E.D., Allard, M.F. and Johnson, J.D., 2012. Cardiac ryanodine receptors control heart rate and rhythmicity in adult mice, Cardiovasc Res. 96, 372-80.

Brunner, M., Peng, X., Liu, G.X., Ren, X.Q., Ziv, O., Choi, B.R., Mathur, R., Hajjiri, M., Odening, K.E., Steinberg, E., Folco, E.J., Pringa, E., Centracchio, J., Macharzina, R.R., Donahay, T., Schofield, L., Rana, N., Kirk, M., Mitchell, G.F., Poppas, A., Zehender, M. and Koren, G., 2008. Mechanisms of cardiac arrhythmias and sudden death in transgenic rabbits with long QT syndrome, J Clin Invest. 118, 2246-59.

Charpentier, E. and Doudna, J.A., 2013. Biotechnology: Rewriting a genome, Nature. 495, $50-1$.

Choi, J.G., Dang, Y., Abraham, S., Ma, H., Zhang, J., Guo, H., Cai, Y., Mikkelsen, J.G., Wu, H., Shankar, P. and Manjunath, N., 2016. Lentivirus pre-packed with Cas9 protein for safer gene editing, Gene Ther.

Decker, J.A., Rossano, J.W., Smith, E.O., Cannon, B., Clunie, S.K., Gates, C., Jefferies, J.L., Kim, J.J., Price, J.F., Dreyer, W.J., Towbin, J.A. and Denfield, S.W., 2009. Risk factors and mode of death in isolated hypertrophic cardiomyopathy in children, $\mathrm{J}$ Am Coll Cardiol. 54, 250-4.

Ding, Y., Wang, Y., Zhu, H., Fan, J., Yu, L., Liu, G. and Liu, E., 2011. Hypertriglyceridemia and delayed clearance of fat load in transgenic rabbits expressing human apolipoprotein CIII, Transgenic Res. 20, 867-75.

Duranthon, V., Beaujean, N., Brunner, M., Odening, K.E., Santos, A.N., Kacskovics, I., Hiripi, L., Weinstein, E.J. and Bosze, Z., 2012. On the emerging role of rabbit as human disease model and the instrumental role of novel transgenic tools, Transgenic Res. 21, 699-713.

Duverger, N., Kruth, H., Emmanuel, F., Caillaud, J.M., Viglietta, C., Castro, G., Tailleux, A., Fievet, C., Fruchart, J.C., Houdebine, L.M. and Denefle, P., 1996. Inhibition of atherosclerosis development in cholesterol-fed human apolipoprotein A-I-transgenic rabbits, Circulation. 94, 713-7.

Fan, J., Ji, Z.S., Huang, Y., de Silva, H., Sanan, D., Mahley, R.W., Innerarity, T.L. and Taylor, J.M., 1998. Increased expression of apolipoprotein $\mathrm{E}$ in transgenic rabbits results in reduced levels of very low density lipoproteins and an accumulation of low density lipoproteins in plasma, J Clin Invest. 101, 2151-64.

Fan, J., Kitajima, S., Watanabe, T., Xu, J., Zhang, J., Liu, E. and Chen, Y.E., 2015. Rabbit models for the study of human atherosclerosis: from pathophysiological mechanisms to translational medicine, Pharmacol Ther. 146, 104-19. 
Fan, J., McCormick, S.P., Krauss, R.M., Taylor, S., Quan, R., Taylor, J.M. and Young, S.G., 1995. Overexpression of human apolipoprotein B-100 in transgenic rabbits results in increased levels of LDL and decreased levels of HDL, Arterioscler Thromb Vasc Biol. $15,1889-99$.

Fan, J., Shimoyamada, H., Sun, H., Marcovina, S., Honda, K. and Watanabe, T., 2001. Transgenic rabbits expressing human apolipoprotein(a) develop more extensive atherosclerotic lesions in response to a cholesterol-rich diet, Arterioscler Thromb Vasc Biol. 21, 88-94.

Fan, J., Wang, J., Bensadoun, A., Lauer, S.J., Dang, Q., Mahley, R.W. and Taylor, J.M., 1994. Overexpression of hepatic lipase in transgenic rabbits leads to a marked reduction of plasma high density lipoproteins and intermediate density lipoproteins, Proc Natl Acad Sci U S A. 91, 8724-8.

Febbraio, M., Podrez, E.A., Smith, J.D., Hajjar, D.P., Hazen, S.L., Hoff, H.F., Sharma, K. and Silverstein, R.L., 2000. Targeted disruption of the class B scavenger receptor CD36 protects against atherosclerotic lesion development in mice, J Clin Invest. 105, 104956.

Flisikowska, T., Thorey, I.S., Offner, S., Ros, F., Lifke, V., Zeitler, B., Rottmann, O., Vincent, A., Zhang, L., Jenkins, S., Niersbach, H., Kind, A.J., Gregory, P.D., Schnieke, A.E. and Platzer, J., 2011. Efficient immunoglobulin gene disruption and targeted replacement in rabbit using zinc finger nucleases, PLoS One. 6, e21045.

Grabundzija, I., Irgang, M., Mates, L., Belay, E., Matrai, J., Gogol-Doring, A., Kawakami, K., Chen, W., Ruiz, P., Chuah, M.K., VandenDriessche, T., Izsvak, Z. and Ivics, Z., 2010. Comparative analysis of transposable element vector systems in human cells, Mol Ther. 18, 1200-9.

Hammer, R.E., Pursel, V.G., Rexroad, C.E., Jr., Wall, R.J., Bolt, D.J., Ebert, K.M., Palmiter, R.D. and Brinster, R.L., 1985. Production of transgenic rabbits, sheep and pigs by microinjection, Nature. 315, 680-3.

Haurwitz, R.E., Jinek, M., Wiedenheft, B., Zhou, K. and Doudna, J.A., 2010. Sequence- and structure-specific RNA processing by a CRISPR endonuclease, Science. 329, 1355-8.

Hoeg, J.M., Santamarina-Fojo, S., Berard, A.M., Cornhill, J.F., Herderick, E.E., Feldman, S.H., Haudenschild, C.C., Vaisman, B.L., Hoyt, R.F., Jr., Demosky, S.J., Jr., Kauffman, R.D., Hazel, C.M., Marcovina, S.M. and Brewer, H.B., Jr., 1996. Overexpression of lecithin:cholesterol acyltransferase in transgenic rabbits prevents diet-induced atherosclerosis, Proc Natl Acad Sci U S A. 93, 11448-53.

Huang, Y., Schwendner, S.W., Rall, S.C., Jr., Sanan, D.A. and Mahley, R.W., 1997. Apolipoprotein E2 transgenic rabbits. Modulation of the type III hyperlipoproteinemic phenotype by estrogen and occurrence of spontaneous atherosclerosis, J Biol Chem. 272, 22685-94.

Ichikawa, T., Kitajima, S., Liang, J., Koike, T., Wang, X., Sun, H., Okazaki, M., Morimoto, M., Shikama, H., Watanabe, T., Yamada, N. and Fan, J., 2004. Overexpression of lipoprotein lipase in transgenic rabbits leads to increased small dense LDL in plasma and promotes atherosclerosis, Lab Invest. 84, 715-26.

Ishibashi, S., Brown, M.S., Goldstein, J.L., Gerard, R.D., Hammer, R.E. and Herz, J., 1993. Hypercholesterolemia in low density lipoprotein receptor knockout mice and its reversal by adenovirus-mediated gene delivery, J Clin Invest. 92, 883-93.

Ivics, Z., Hiripi, L., Hoffmann, O.I., Mates, L., Yau, T.Y., Bashir, S., Zidek, V., Landa, V., Geurts, A., Pravenec, M., Rulicke, T., Bosze, Z. and Izsvak, Z., 2014. Germline transgenesis in rabbits by pronuclear microinjection of Sleeping Beauty transposons, Nat Protoc. 9, 794-809. 
Izsvak, Z., Ivics, Z. and Plasterk, R.H., 2000. Sleeping Beauty, a wide host-range transposon vector for genetic transformation in vertebrates, J Mol Biol. 302, 93-102.

James, J., Sanbe, A., Yager, K., Martin, L., Klevitsky, R. and Robbins, J., 2000. Genetic manipulation of the rabbit heart via transgenesis, Circulation. 101, 1715-21.

Ji, D., Zhao, G., Songstad, A., Cui, X. and Weinstein, E.J., 2015. Efficient creation of an APOE knockout rabbit, Transgenic Res. 24, 227-35.

Joung, J.K. and Sander, J.D., 2013. TALENs: a widely applicable technology for targeted genome editing, Nat Rev Mol Cell Biol. 14, 49-55.

Katter, K., Geurts, A.M., Hoffmann, O., Mates, L., Landa, V., Hiripi, L., Moreno, C., Lazar, J., Bashir, S., Zidek, V., Popova, E., Jerchow, B., Becker, K., Devaraj, A., Walter, I., Grzybowksi, M., Corbett, M., Filho, A.R., Hodges, M.R., Bader, M., Ivics, Z., Jacob, H.J., Pravenec, M., Bosze, Z., Rulicke, T. and Izsvak, Z., 2013. Transposon-mediated transgenesis, transgenic rescue, and tissue-specific gene expression in rodents and rabbits, FASEB J. 27, 930-41.

Kitajima, S., Jin, Y., Koike, T., Yu, Y., Liu, E., Shiomi, M., Marcovina, S.M., Morimoto, M., Watanabe, T. and Fan, J., 2007. Lp(a) enhances coronary atherosclerosis in transgenic Watanabe heritable hyperlipidemic rabbits, Atherosclerosis. 193, 269-76.

Kitajima, S., Liu, E., Morimoto, M., Koike, T., Yu, Y., Watanabe, T., Imagawa, S. and Fan, J., 2005. Transgenic rabbits with increased VEGF expression develop hemangiomas in the liver: a new model for Kasabach-Merritt syndrome, Lab Invest. 85, 1517-27.

Kleinstiver, B.P., Pattanayak, V., Prew, M.S., Tsai, S.Q., Nguyen, N.T., Zheng, Z. and Joung, J.K., 2016. High-fidelity CRISPR-Cas9 nucleases with no detectable genome-wide off-target effects, Nature. 529, 490-5.

Koike, T., Kitajima, S., Yu, Y., Li, Y., Nishijima, K., Liu, E., Sun, H., Waqar, A.B., Shibata, N., Inoue, T., Wang, Y., Zhang, B., Kobayashi, J., Morimoto, M., Saku, K., Watanabe, T. and Fan, J., 2009. Expression of human apoAII in transgenic rabbits leads to dyslipidemia: a new model for combined hyperlipidemia, Arterioscler Thromb Vasc Biol. 29, 2047-53.

Liang, J., Liu, E., Yu, Y., Kitajima, S., Koike, T., Jin, Y., Morimoto, M., Hatakeyama, K., Asada, Y., Watanabe, T., Sasaguri, Y., Watanabe, S. and Fan, J., 2006. Macrophage metalloelastase accelerates the progression of atherosclerosis in transgenic rabbits, Circulation. 113, 1993-2001.

Lieber, M.R., 1999. The biochemistry and biological significance of nonhomologous DNA end joining: an essential repair process in multicellular eukaryotes, Genes Cells. 4, 7785.

Liu, E., Morimoto, M., Kitajima, S., Koike, T., Yu, Y., Shiiki, H., Nagata, M., Watanabe, T. and Fan, J., 2007. Increased expression of vascular endothelial growth factor in kidney leads to progressive impairment of glomerular functions, J Am Soc Nephrol. 18, 2094104.

Major, P., Baczko, I., Hiripi, L., Odening, K.E., Juhasz, V., Kohajda, Z., Horvath, A., Seprenyi, G., Kovacs, M., Virag, L., Jost, N., Prorok, J., Ordog, B., Doleschall, Z., Nattel, S., Varro, A. and Bosze, Z., 2016. A novel transgenic rabbit model with reduced repolarization reserve: long QT syndrome caused by a dominant-negative mutation of KCNE1 gene, Br J Pharmacol.

Mani, M., Smith, J., Kandavelou, K., Berg, J.M. and Chandrasegaran, S., 2005. Binding of two zinc finger nuclease monomers to two specific sites is required for effective double-strand DNA cleavage, Biochem Biophys Res Commun. 334, 1191-7.

Marian, A.J., 2005. On mice, rabbits, and human heart failure, Circulation. 111, 2276-9. 
Marian, A.J., Wu, Y., Lim, D.S., McCluggage, M., Youker, K., Yu, Q.T., Brugada, R., DeMayo, F., Quinones, M. and Roberts, R., 1999. A transgenic rabbit model for human hypertrophic cardiomyopathy, J Clin Invest. 104, 1683-92.

Masson, D., Deckert, V., Gautier, T., Klein, A., Desrumaux, C., Viglietta, C., Pais de Barros, J.P., Le Guern, N., Grober, J., Labbe, J., Menetrier, F., Ripoll, P.J., Leroux-Coyau, M., Jolivet, G., Houdebine, L.M. and Lagrost, L., 2011. Worsening of diet-induced atherosclerosis in a new model of transgenic rabbit expressing the human plasma phospholipid transfer protein, Arterioscler Thromb Vasc Biol. 31, 766-74.

Mates, L., Chuah, M.K., Belay, E., Jerchow, B., Manoj, N., Acosta-Sanchez, A., Grzela, D.P., Schmitt, A., Becker, K., Matrai, J., Ma, L., Samara-Kuko, E., Gysemans, C.,

Pryputniewicz, D., Miskey, C., Fletcher, B., VandenDriessche, T., Ivics, Z. and Izsvak, Z., 2009. Molecular evolution of a novel hyperactive Sleeping Beauty transposase enables robust stable gene transfer in vertebrates, Nat Genet. 41, 753-61.

Matsuda, S., Yamashita, A., Sato, Y., Kitajima, S., Koike, T., Sugita, C., Moriguchi-Goto, S., Hatakeyama, K., Takahashi, M., Koshimoto, C., Matsuura, Y., Iwakiri, T., Chen, Y.E., Fan, J. and Asada, Y., 2011. Human C-reactive protein enhances thrombus formation after neointimal balloon injury in transgenic rabbits, J Thromb Haemost. 9, 201-8.

Miller, I., Rogel-Gaillard, C., Spina, D., Fontanesi, L. and de Almeida, A.M., 2014. The rabbit as an experimental and production animal: from genomics to proteomics, Curr Protein Pept Sci. 15, 134-45.

Odening, K.E., Hyder, O., Chaves, L., Schofield, L., Brunner, M., Kirk, M., Zehender, M., Peng, X. and Koren, G., 2008. Pharmacogenomics of anesthetic drugs in transgenic LQT1 and LQT2 rabbits reveal genotype-specific differential effects on cardiac repolarization, Am J Physiol Heart Circ Physiol. 295, H2264-72.

Patel, R., Nagueh, S.F., Tsybouleva, N., Abdellatif, M., Lutucuta, S., Kopelen, H.A., Quinones, M.A., Zoghbi, W.A., Entman, M.L., Roberts, R. and Marian, A.J., 2001. Simvastatin induces regression of cardiac hypertrophy and fibrosis and improves cardiac function in a transgenic rabbit model of human hypertrophic cardiomyopathy, Circulation. 104, 317-24.

Reis, A.H., Macdonald, B.T., Feistel, K., Brito, J.M., Amado, N.G., Xu, C., Abreu, J.G. and He, X., 2014. Expression and evolution of the Tikil and Tiki2 genes in vertebrates, Int J Dev Biol. 58, 355-62.

Rouy, D., Duverger, N., Lin, S.D., Emmanuel, F., Houdebine, L.M., Denefle, P., Viglietta, C., Gong, E., Rubin, E.M. and Hughes, S.D., 1998. Apolipoprotein(a) yeast artificial chromosome transgenic rabbits. Lipoprotein(a) assembly with human and rabbit apolipoprotein B, J Biol Chem. 273, 1247-51.

Sanbe, A., James, J., Tuzcu, V., Nas, S., Martin, L., Gulick, J., Osinska, H., Sakthivel, S., Klevitsky, R., Ginsburg, K.S., Bers, D.M., Zinman, B., Lakatta, E.G. and Robbins, J., 2005. Transgenic rabbit model for human troponin I-based hypertrophic cardiomyopathy, Circulation. 111, 2330-8.

Senthil, V., Chen, S.N., Tsybouleva, N., Halder, T., Nagueh, S.F., Willerson, J.T., Roberts, R. and Marian, A.J., 2005. Prevention of cardiac hypertrophy by atorvastatin in a transgenic rabbit model of human hypertrophic cardiomyopathy, Circ Res. 97, 285-92.

Sharma, R., Anguela, X.M., Doyon, Y., Wechsler, T., DeKelver, R.C., Sproul, S., Paschon, D.E., Miller, J.C., Davidson, R.J., Shivak, D., Zhou, S., Rieders, J., Gregory, P.D., Holmes, M.C., Rebar, E.J. and High, K.A., 2015. In vivo genome editing of the albumin locus as a platform for protein replacement therapy, Blood. 126, 1777-84.

Shen, J., Herderick, E., Cornhill, J.F., Zsigmond, E., Kim, H.S., Kuhn, H., Guevara, N.V. and Chan, L., 1996. Macrophage-mediated 15-lipoxygenase expression protects against atherosclerosis development, J Clin Invest. 98, 2201-8. 
Shen, J., Kuhn, H., Petho-Schramm, A. and Chan, L., 1995. Transgenic rabbits with the integrated human 15-lipoxygenase gene driven by a lysozyme promoter: macrophagespecific expression and variable positional specificity of the transgenic enzyme, FASEB J. 9, 1623-31.

Song, J., Zhong, J., Guo, X., Chen, Y., Zou, Q., Huang, J., Li, X., Zhang, Q., Jiang, Z., Tang, C., Yang, H., Liu, T., Li, P., Pei, D. and Lai, L., 2013. Generation of RAG 1- and 2deficient rabbits by embryo microinjection of TALENs, Cell Res. 23, 1059-62.

Streubel, J., Blucher, C., Landgraf, A. and Boch, J., 2012. TAL effector RVD specificities and efficiencies, Nat Biotechnol. 30, 593-5.

Suzuki, T., Palmer, B.M., James, J., Wang, Y., Chen, Z., VanBuren, P., Maughan, D.W., Robbins, J. and LeWinter, M.M., 2009. Effects of cardiac myosin isoform variation on myofilament function and crossbridge kinetics in transgenic rabbits, Circ Heart Fail. 2, 334-41.

Tebas, P., Stein, D., Tang, W.W., Frank, I., Wang, S.Q., Lee, G., Spratt, S.K., Surosky, R.T., Giedlin, M.A., Nichol, G., Holmes, M.C., Gregory, P.D., Ando, D.G., Kalos, M., Collman, R.G., Binder-Scholl, G., Plesa, G., Hwang, W.T., Levine, B.L. and June, C.H., 2014. Gene editing of CCR5 in autologous CD4 T cells of persons infected with HIV, N Engl J Med. 370, 901-10.

Yamada, S., Wang, K.Y., Tanimoto, A., Fan, J., Shimajiri, S., Kitajima, S., Morimoto, M., Tsutsui, M., Watanabe, T., Yasumoto, K. and Sasaguri, Y., 2008. Matrix metalloproteinase 12 accelerates the initiation of atherosclerosis and stimulates the progression of fatty streaks to fibrous plaques in transgenic rabbits, Am J Pathol. 172, 1419-29.

Yamanaka, S., Balestra, M.E., Ferrell, L.D., Fan, J., Arnold, K.S., Taylor, S., Taylor, J.M. and Innerarity, T.L., 1995. Apolipoprotein B mRNA-editing protein induces hepatocellular carcinoma and dysplasia in transgenic animals, Proc Natl Acad Sci U S A. 92, 8483-7.

Yan, Q., Zhang, Q., Yang, H., Zou, Q., Tang, C., Fan, N. and Lai, L., 2014. Generation of multi-gene knockout rabbits using the Cas9/gRNA system, Cell Regen (Lond). 3, 12.

Yang, D., Xu, J., Zhu, T., Fan, J., Lai, L., Zhang, J. and Chen, Y.E., 2014. Effective gene targeting in rabbits using RNA-guided Cas9 nucleases, J Mol Cell Biol. 6, 97-9.

Yang, D., Zhang, J., Xu, J., Zhu, T., Fan, Y., Fan, J. and Chen, Y.E., 2013. Production of apolipoprotein C-III knockout rabbits using zinc finger nucleases, J Vis Exp. e50957.

Yin, M., Jiang, W., Fang, Z., Kong, P., Xing, F., Li, Y., Chen, X. and Li, S., 2015. Generation of hypoxanthine phosphoribosyltransferase gene knockout rabbits by homologous recombination and gene trapping through somatic cell nuclear transfer, Sci Rep. 5 , 16023.

Zakhartchenko, V., Flisikowska, T., Li, S., Richter, T., Wieland, H., Durkovic, M., Rottmann, O., Kessler, B., Gungor, T., Brem, G., Kind, A., Wolf, E. and Schnieke, A., 2011. Cell-mediated transgenesis in rabbits: chimeric and nuclear transfer animals, Biol Reprod. 84, 229-37. 
A.

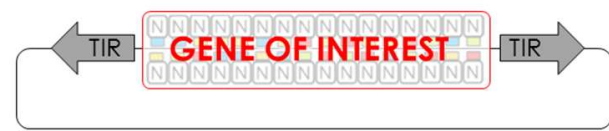

TRANSPOSON VECTOR

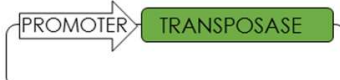

SYNTHETIC

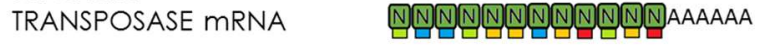

B.

TRANSPOSON EXCISION
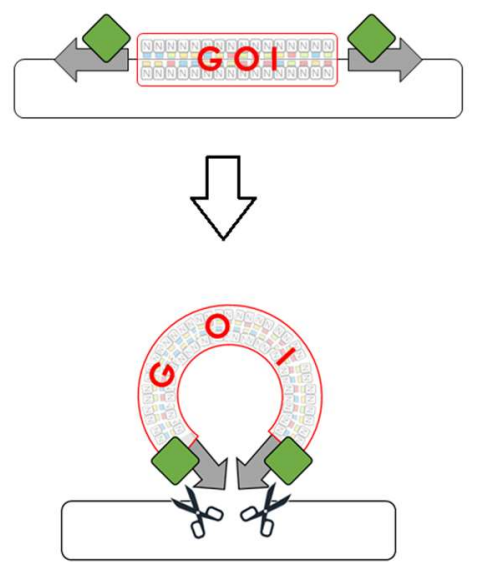

GENOMIC INTEGRATION
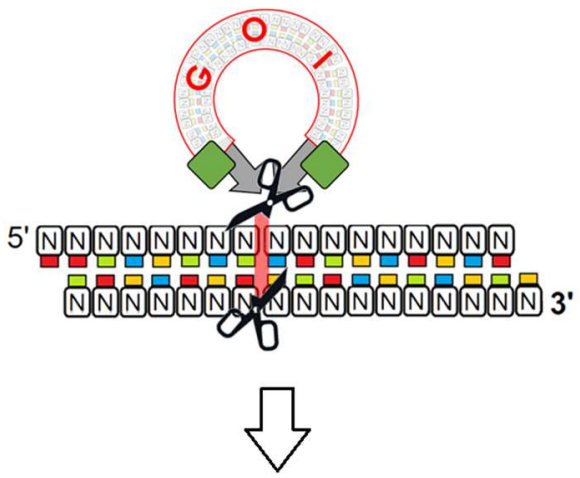

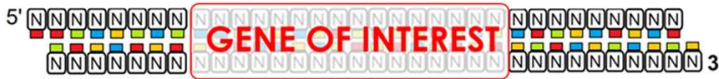

Figure 1. 


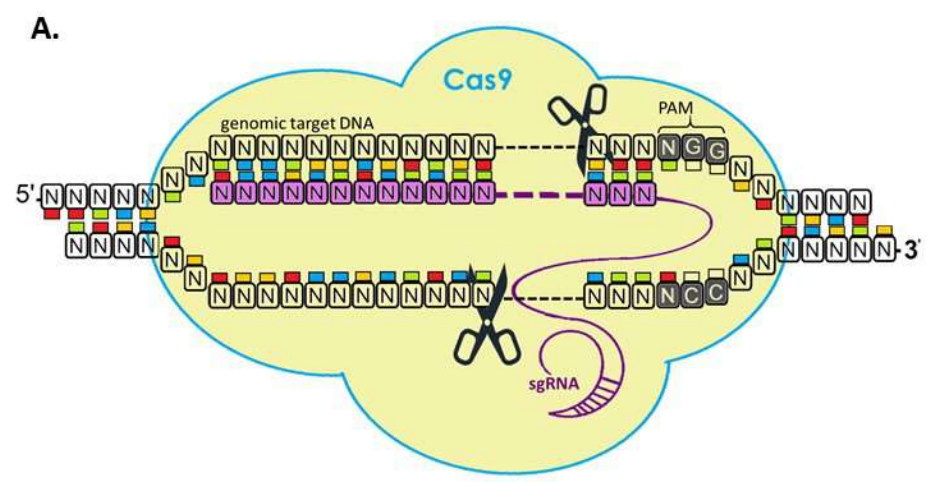

B.
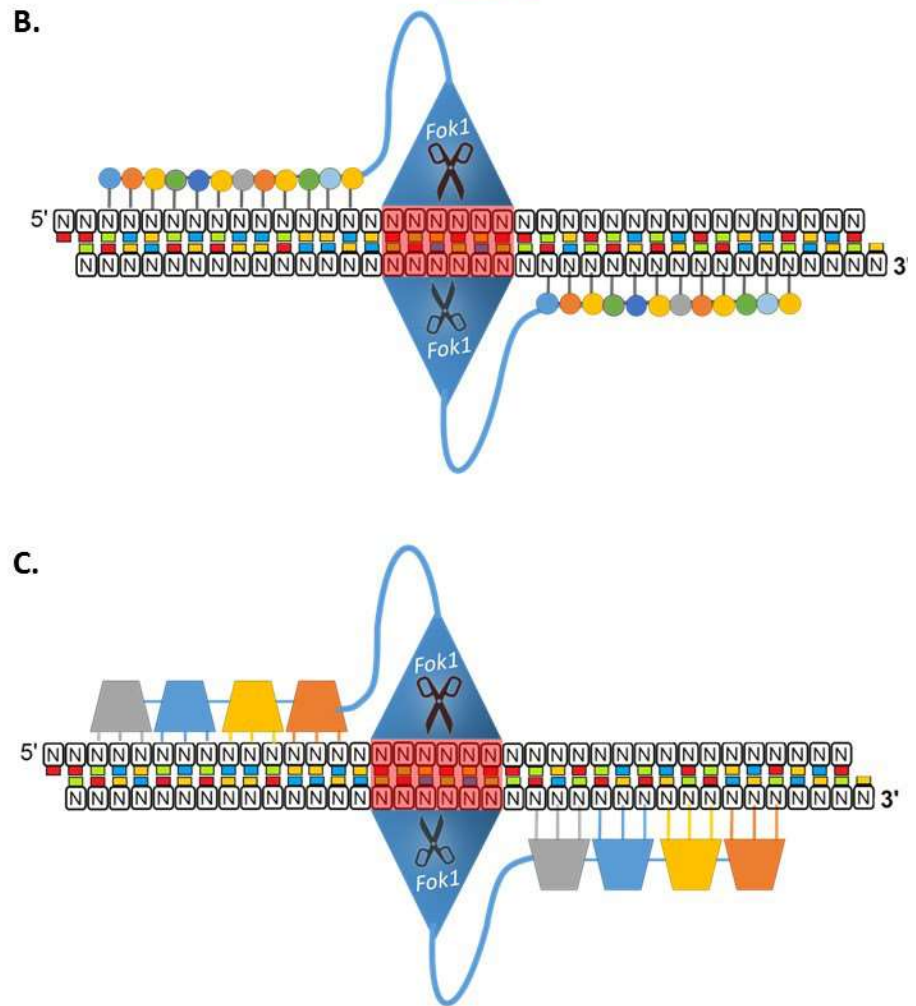

Figure 2 